\title{
Macedonian Medical Master of Science Theses in Public Health Defended in 2011
}

\author{
Macedonian Journal of Medical Sciences
}

Institute of Immunobiology and Human Genetics, Faculty of Medicine, University “Ss Cyril and Methodius", Skopje, Republic of Macedonia

\begin{abstract}
Citation: Macedonian Journal of Medical Sciences. Macedonian Medical Master of Science Theses in Public Health Defended in 2007-2010. Maced J Med Sci. 2012 Oct 15; 5(3):356-365. http://dx doi.org/10.3889/MJMS.1857http://dx.dol.org/10.3889/MJMS.1857-

Key words: Medical Publications; Medical research; Master of Sciences; Public Health; Republic of Macedonia.

Correspondence: Macedonian Journal of Medica Sciences. Institute of Immunobiology and Human Genetics, Faculty of Medicine, University "Ss Cyril and Methodius", Skopje, Republic of Macedonia. 50 Divizija No 16, PO Box 60, 1109 Skopje, Republic of Macedonia. Telephone: +389 2 3110556. Telefax: +389 23110558 . EMail: mjms@ukim.edu.mk

Received: 12-Oct-2011; Revised:10-Nov-2011; Accepted: 14-Nov-2011; Online first:17-Nov-2011 Copyright: $\odot 2012$ Macedonian Journal of Medical Sciences. This is an open-access article distributed under the terms of the Creative Commons Attribution License, which permits unrestricted use, distribution, and reproduction in any medium provided the original author and source are credited.

Competing Interests: The author have declared that no competing interests exist.
\end{abstract}

\section{Abstract}

We present English abstracts of MSc theses in Public Health defended in 2011 at the Faculty of Medicine, University "Ss Cyril and Methodius", Skopje, Republic of Macedonia. English summaries are published as they are translated by authors and included in the final version of defended MSc. Macedonian Medical Master of Science (MSc) theses are deposited in the Central Medical Library and National and University Library "St. Kliment Ohridski" in Skopje, Republic of Macedonia.

At the Faculty of Medicine in Skopje 15 MSc theses were defended in 2011, two MSc are without abstarcts (13.3\%) (Angelina Blazevska. Satisfaction of the patients with the services of a specialist consultative activity in Skopje [MSc thesis]. Skopje, Republic of Macedonia: Center for Public Health, Faculty of Medicine, University "Ss Cyril and Methodius"; 2011; Stojan Bajraktarov. Impact of the work with night shifts on the quality of the helth among health workers - an opportunity for public health action [MSc thesis]. Skopje, Republic of Macedonia: Cathedra of Occupational Medicine, Center for Public Health, University "Ss Cyril and Methodius"; 2011) and four MSc are without Key words (26.7\%).

Editorial Board does not take any responsibility either for the content, nor the quality of the abstracts. We have to repeat that primary responsibility for the quality of the MSc theses belongs to the mentors, to the institutions they are representing, to the Vice-Dean of science, and to Reponsible person for MSc in Public Health. All of them should be more actively involved in the preparation of Master of Science theses in Public Health in order international standards to be achieved.

\begin{abstract}
Angelina Blazevska. Satisfaction of the patients with the services of a specialist - consultative activity in Skopje [MSc thesis]. Skopje, Republic of Macedonia: Center for Public Health, Faculty of Medicine, University "Ss Cyril and Methodius"; 2011.
\end{abstract}

Abstract not available.

Key words: Not available.
Defended: February 28, 2011.

Mentor: Prof. Dr. Elena Kjosevska.

Stojan Bajraktarov. Impact of the work with night shifts on the quality of the helth among health workers - an opportunity for public health action [MSc thesis]. Skopje, Republic of Macedonia: Cathedra of 
Occupational Medicine, Center for Public Health, University "Ss Cyril and Methodius"; 2011.

Abstract not available

Key words: Not available

Defended: March 25, 2011.

Mentor: Prof. Dr. Jordan Minov.

Meri Shapuric. Public health aspect of the oral health among the elderly people over 65 years old in The Republic of Macedonia - situation and implications for strategic planning [MSc thesis]. Skopje, Republic of Macedonia: Cathedra of Social Medicine, Center for Public Health, Faculty of Medicine, University "Ss Kiril and Metodij"; 2011.

Introduction: Throughout the world a demographic revolution is underway and the proportion of older people is growing faster than any other age group. Approximately 600 million people are aged 60 years and this number will double by 2025 year.

The oral health is defined as: normal (standard) condition of interconnection of the oral and close related tissues, a state which enables a person to eat, speak and socialize, with the absence of sickness, discomfort and embarrassment, contributing to the person's wellbeing, WHO.

The oral health be neglected at older age and has to be continuously taken care off. The influence of oral diseases on the elderly health condition, as well as the importance of the oral health are joined in the suggestions concerning health in the WHO "Ageing and Life Course Program".

Main objective: The main objective of this paper is the oral health assessment, as wel as to determine the public health aspects of oral health and the impact of the quality of life on the elderly over 65 years old with the aim to present recommendations regarding proper indications for dental inspection and implications for strategy planning.

Material and methods: A transversal (cross-sectional) study was conducted in 10 specialized dental practices, located in 10 Macedonian cities from the eight statistical regions in RM during the period May-August. The sample was determined on the basis of 366 respondents and calculated with statistical software PEPI 4.044, (CI 95\%). The statistical testing was performed by SPSS 16.0 software.
Testing the statistical significance of the differences in the distribution of the obtained answers was conducted by using a) Cross-tabulation and Chi-square test for categorical variables, Kolmogorov-Smirnov test and Kruskal-Wallis test also, b) for continuous variables: ttest for independent variables and Mann-Withney test for continuous variables.

All statistical tests were performed by applying the required statistical significance level of $p<0.05$ (results regarded as 'significant') and the results with $p>0.05$ as 'absence of evidence of a difference'.

Results: The average age of the respondents is in the range of $69.3 \pm 4.98$ years from 65 to 89 years. The gender distribution is higher for men (48.09\%), compared to a lower distribution for women (51.9\%). Regarding the ethnic origin most frequent are Macedonians (85.25\%), followed by Albanians (12.3\%) and (2.5\%) respondents from the Roma Ethnicity. The majority of the respondents had secondary education (41.5\%), 13.7\% had collage degree and $11.75 \%$ are with higher degree. The dental inspection of the respondents, regarding the typified edentulousness has shown that $252(68.8 \%)$ of the patients have complete edentulism, 50 (13.76\%) have partial edentulism and mixed edentulism has been recorded in $64(17.49 \%)$ of the patientis. The obtained results for the oral functioning have shown that the average score of the OHIP-14 Questionnaire among the respondents that differ with dental status are highly statistically significant. The dental status has highly significant influence on the answers of the respondents regarding their psychological functioning. There is a slight difference between the respondents with different dental status, regarding the consequences from the implications of the removable dentures in the sphere of social functioning.

Conclusion: Î nthe basis of the conducted score analyses obtained by the application of the OHIP-14 score questionnaire, a conclusion was brought that the oral health of the elderly over 65 is relatively good, satisfactory, concerning the presented value of the score which was no higher than 43 (max. value that represents bad oral health - 52). A conclusion was made that the OHIP-14 instrument is a valid, reliable, instrument which can be used in the determination of the impact of the oral health on the quality of life of the patients and in the dental and prosthetics work generally. There are is a need to carry out and conduct preventive strategies, educational strategies to rise the public awareness, skill developing strategies (expansion of the Dental insurance plans and their availability), strategies for additional trainings of the 
health professionals, in take care of elderly people.

Key words: oral health; the elderly population group over 65; OHIP-14 Questionnaire; oral functioning; psychological response to oral malfunctioning, social functioning; preventive strategies; oral health promotion.

Defended: March 30, 2011.

Mentor: Prof. Dr. Fimka Tozija.

Svetlana Gjorgjioska. Public health aspects of the occupational injuries in Republic of Macedonia [MSc thesis]. Skopje, Republic of Macedonia: Center for Public Health, Faculty of Medicine, University "Ss Cyril and Methodius"; 2011.

Introduction: Injuries at work pose a great threat to the health of the working population worldwide. 270 million employees are injured at work every year and 360000 among them are fatal. The global burden of diseases injuries at work is calculated to be 10.5 million DALY's or in other words: 3.5 years lost life for 1000 workers globally for one year. Besides lost life, temporary and long - life disability, there are also absenteeism, production losses on company, national and global economy level (4\% per GDP or 1.3 trillion US dollars annually), medical, compensation and insurance costs etc.

Main objective: The main objective of this paper is to determine the public health aspects of the occupational injuries by assessment of the distribution, characteristics and circumstances of their occurrence.

Material and methods: Retrospective analytical study was conducted by studying injuries at work reported for the year 2009, at the regional departments of the Ministry of Labour and Social Policy in Macedonia, designed according to the ESAW (European statistics on accidents at work) methodology, for a total of 448 injuries at work. The inspection documents from supervision and other documentation were classified including workers data, the data of the companies where the injuries occurred and the causation elements data. The safety and health measures (personal and collective protective equipment, preventive occupational health examinations and safety and health training of the injured workers were also included).

The obtained results were statistically analyzed by using the statistical program: Statistika for Windows 7.0 and adequate statistical methods for statistical significance testing applying required statistical significance level of p $<0.05$ (results regarded as "significant").

Results: The most frequent categories of injured workers are: male workers (76.8\%), secondary graduated (72.23\%) and ethnic Macedonians. The workers of age 25-54 were most commonly injured (80\%). Around half of the total of injuries at work took place in the industrial companies, at the industrial sites and companies with 500 and more workers engaged and most frequently at the geographical location in Skopje. The injured workers were most commonly engaged on a legal basis (93.97\%), and among them most prevalent were those hired on the basis of a permanent contacts (79.27\%). The majority of the injured workers with occupation at risk like craft workers, workers operating manual non - power and power - driven tools, machine and site operators and workers with elementary occupations (80\%) were most prevalent. Half of all injured workers had job tenure up to 5 years. The majority of all workers were injured in the morning shift (76\%) and slightly more in June among all months. Wounds and superficial injuries are the most common type of injuries (36.26\%) followed by fractures (30.72\%). The upper limbs (40.42\%) and lower limbs (31.87\%) were mostly affected.

The falls were the most frequent mechanism of injuries and the workers were most of the time in motion while they were injured regarding their specific working activity. Slips, falls etc occurred in one third out of all deviations leading to injuries at work.

Conclusion: The lack of conducted preventive measures concerning safety and health at work was the most common case when injuries occurred (personal and collective protective measures, preventive occupational medical exams with the evaluation of the workability). The workers training for safety and health was mostly conducted, but not in the accordance with the present Safety and Health Law. Most frequently injured were male workers in the processing industry companies. There is a difference among separate mechanisms of injuries in different activities and the falls and strikes by moving part took place mostly in industrial companies. Deviations that led to injuries regarding loss of the control of the worker most frequently took place in industrial and building construction companies and represent human and procedural mistakes. Workers with occupations at risk and at the age of 25-44 are most frequently among the injured with contact with material agents of mechanical source.

Key words: injuries at work; workers; mechanism of injuries; specific activity; deviations; conducted safety and health measures; prevention. 
Defended: April 1, 2011.

Mentor: Prof. Dr. Mome Spasovski.

Arse Petreski. Epidemiological and socio-ethical aspects of hepatitis $\mathrm{C}$ as a public health problem in Republic of Macedonia [MSc thesis]. Skopje, Republic of Macedonia: Center for Public Health, Faculty of Medicine, University "Ss Cyril and Methodius"; 2011.

Hepatitis $C$ is blood transmisable disease at the liver, the various that makes Hepatitis $C$ and is called Hepatitis $C$ virus, in capsule RNK virus of the family Flaviviridae. A very important characteristic about the virus is its relatively mutability on its genome that is connected with high ability to cause chronical disease, the genotype is not connected with the development of the disease, but influence the durability and the success of the treatment, and covers great geographical areas.

Usual ways of transmising the virus or the risk factors are: blood transfusions, careless medical workers that use their instruments and needles not properly, while using illegal drugs, other contacts of blood by blood, piercing the body with unsterilized instruments, tattooing with unsterilized needles, using some personal things by other people like toothbrush, scissors for nails, transmising the disease from mother to unburned chiledvertical transmision, during the dialyses sexual intercourse, transplanting tissues and organs which have not been tasted before, use of internasel cocein and other instruments used for taking drugs.

The diagnosis of Hepatitis $\mathrm{C}$ is set by a clinical picture, an epidemiological questionare, and blood analysis.

The treatment of the disease and its success depend on genotype of the disease, age, and exposure of the risk factors.

The Hepatitis $\mathrm{C}$ problems are covered from the medical area and public health and with its wideness that presents its implications are taken from the public health, economical and social, ethical aspects in Republic in Macedonia.

Key words: Hepatitis C; incidence; prevalence; virus disease; risk factors; social and ethical aspect.

Defended: April 4, 2011.

Mentor: Prof. Dr. Rozalinda Isjanovska.
Dejan Krstic. Cost-effectiveness analysis on the conventional and alternative approach in the treatment of massive haemorrhage in critically ill patients with polytrauma [MSc thesis]. Skopje, Republic of Macedonia: Center for Public Health, Faculty of Medicine, University "Ss Cyril and Methodius"; 2011.

Introduction. Uncontrolled massive haemorrhage in patients with polytrauma is the leading cause of early inhospital mortality. Any proposed new intervention in these patients must be weighed carefully against its costs and efficacy. To adopt the use of such interventions without consideration of their potential effect on survival or the prevention of complications will inevitably lead to inappropriate use in some cases and increased cost for very little benefit. The cost-effectiveness analysis has now become an established tool in assessment of costs and efficacy of new interventions before their adoption.

Materials and methods. The retrospective research involved statistical analyses and economic evaluation using data of critically ill patients with polytrauma and massive haemorrhage treated with blood and blood products at the clinic for anaesthesia, reanimation and intensive care at the clinical in Skopje. The prospective research involved statistical analyses and economic evaluation using data of the critically ill patients with polytrauma and massive haemorrhage treated with recombinant factor VIla ( $\mathrm{rFVlla)}$ at the same clinic.

Results. Results showed significant statistical difference in favor of the alternative method-rFVlla. In comparison with the retrospective group of patients, the prospective group of patients treated with rFVlla demonstrated successful control of haemorrhage and statistically significant reduction in usage of blood and blood products, intensive care unit length of stay, mortality and treatment costs.

Conclusion. A single intravenous bolus dose of 90 $\mu \mathrm{glkg}$ TT rFVlla may be a cost- effective therapy for control of massive haemorrhage in critically ill patients with polytrauma. In other to confirm this, a detailed costeffectiveness analysis is required.

Key words: polytrauma; massive haemorrhage; blood products; rFVIla; cost-effectiveness analysis.

Defended: June 9, 2011.

Mentor: Prof. Dr. Mome Spasovski.

Natalija Dechovski. Impact of public-health 
determinants of the level of sexual and reproductive health of women in the reproductive period in the Municipality of Shtip [MSc thesis]. Skopje, Republic of Macedonia: Center for Public Health, Faculty of Medicine, University "Ss Cyril and Methodius"; 2011

Background. Reproductive and sexual health is defined as a state of complete physical, mental and social wellbeing and not only the absence of disease for all that is associated with the reproductive system and its functioning, including sexual behavior and sense of sexual well-being. Sexual and reproductive health has a significant impact on the overall health of women, the health of their children, families and the community as a whole.

The main goal of this research was to review the impact of public-health determinants of the level of sexual and reproductive health of women in the reproductive period in the Municipality of Shtip for designing specific programs to improve their sexual and reproductive health.

Material and methods. The survey was conducted by prospective transversal (cross-sectional) study that was based on a database derived from field research on reproductive health of women in the reproductive period of the Municipality of Shtip, with the questionnaire on sexual and reproductive health of women of the Municipality of Shtip. For this survey were processed and analyzed data from the answers of respondents from the Municipality of Shtip in terms of sexual behavior, family planning, pregnancy care and birth, information related to health and abortion and satisfaction with health care. The target population was women in the reproductive period of ten local communities in the Municipality of Shtip aged 15-49 years dividend into 7 age groups. Statistical data analysis was made using the program SPSS 15.0. The variables in the survey are shown as number and percentage. The significance of the differences in the distribution of answers are testing with tests of nonparametric statistics such as: Pearson or $\mathrm{X}^{2}$ test (Chi-square test) for two or more independent samples, Mann-Whitney $U$ - test, Kruskal-Wallis test ANOVA - Analysis of variance and Tukey HSD test. All statistical test were processed by applying the required statistical significance of $p<0.05$, results interpreted as statistically significant. All results are show in tables and graphically.

Results. Sexual behavior of women in the reproductive period of the Municipality of Shtip showed a trend of reducing the age for starting sexual activity and having the first sexual activity before entering into marriage. The median age of first sexual intercourse at women was 17.8 years and only $6.5 \%$ of respondents had first sexual intercourse by entering into marriage. At the age of $15-19$ years, $64.2 \%$ of respondents had first sexual intercourse and $100 \%$ of women up to 24 years already had first sexual experience. Statistically significant difference of $p<0,05$ was obtained from the analysis of age, education level, ethnicity, employment status and place of residence and lack of knowledge about any STIs and their symptoms. The biggest lack of knowledge about any STIs and their symptoms were recorded in the age group $15-19$ years $(23.4 \%, 39.5 \%)$, among respondents with low education (49\%, 56.7\%), Roma and Turkish women (50\%, 5835\%), welfare recipients $(49 \%, 58.8 \%)$ and women from the local community 1 (40\%, 46.7\%). The respondents in the highest percentage of $94.6 \%$ did not use condom during first sexual contact, mostly $69 \%$ didn't use condom during sexual intercourse, and $57.7 \%$ of respondents do not think about the reasons why they are not using condoms. The contraceptive that respondents used in the past 12 months was withdrawal as a methods of contraception used by $53 \%$ of respondents and $21.2 \%$ of condom use. Modern contraceptives were used by only $7.5 \%$ of respondents. It showed statistically significant differences for $p<0.05$ of education level and use of contraceptives so that respondents with high school, college and university education to a greater percentage using contraceptives than those with primary and lower secondary education. In terms of residence and use of contraceptives to confirm the connection to the greater use of contraceptives among women living in the downtown area in the local communities 4 and 6 and lower use in women from the rural local community 10 . The average age of mothers at first marriage was 22.8 years and average age at first live birth was 23.6 years. The highest average number of children have Roma and Turkish women (3 and 2.7), and the lowest number in Vlach and Macedonian women (1.6). The average age of first marriage of 17.7 years is the lowest among Roma women, unlike in Turkish women who enter into the first marriage with average 20.3, Macedonian women with 24.5 and Vlach women with 26.5. The biggest difference is registered between a local community 1 where the average age of first marriage of the respondents was 18.8 years, the average age at first live birth 17.5 years, and the average number of children 3 , unlike in the local community 6 where the average age of first marriage was 24.5 years, the average age of first live birth 25.9 years and average number of children 1.5. Most young people aged 15-24 do not plan their first child (61.5\%, $76.7 \%$ ) and $21 \%$ did not think of that theme. Induced abortion made $19.5 \%$ of the respondents an average of 
1.15 abortions per woman. 20.35\% of Macedonian women made inducted abortus, while $17.5 \%$ Roma women and $20 \%$ of Vlach woman. Respondents made the highest percentage of inducted abortion of $23.3 \%$ from the local community $10.59 .1 \%$ of respondents aged 15-24 years do not know whether abortion carries consequences, $52.6 \%$ did not know who to make the decision, while $47 \%$ believe that the abortion should be prohibited by law. Low level of knowledge about abortion was showed by the women from the Roma nationality and the Muslim religion. From the number of interviewed women who answered the question whether in the pregnancy smoked cigarettes, 35\% answered affirmatively. Of the remaining 65\% nonsmokers, $14.1 \%$ were women who, because knowledge of the facts that smoking is harmful during pregnancy, stop smoking and not smoked during pregnancy. The biggest problem in pregnancy was anemia in 34.3\% and elevated body weight greater than $15 \mathrm{~kg}$ in $10.5 \%$ of respondents. $13.9 \%$ of respondents have given birth by caesarean section. Most delivered by caesarean section are noted in the age group 40-44 years and $45-49$ years (18\% and $16.4 \%)$ compared to age group from $15-19$ years and $20-24$ years where $100 \%$ and $96 \%$ of respondents have birth naturally. Most of the women in the Municipality of Shtip are not attention gynecologist for preventive examination or rarely attend, do not perform preventive PAP smear and breast examination, especially young women of 15- 29 years, as well as the respondents with low and primary education, Roma and Turkish women, unemployed, housewives, redundant workers, students, pupils, welfare recipients and women from local communities 1, 8 and 10. 9.5\% of respondents have not selected gynecologist. Most of the respondents, $57.8 \%$ just party know their reproductive rights, and $26.5 \%$ of the respondents did not know their rights at all. The biggest lack of knowledge about reproductive rights was observed among young people aged from 15-19 years and women aged from 45-49 years, as well as women with low education, women with low socioeconomic status, students, women with Muslim religion, in particular Roma women, and women from local communities 1 and 10.

Conclusion. Sexual behavior of respondents in Shtip is not satisfactory and is influenced by public-health determinants of age, nationality, religious affiliation and place of residence. There is a lower level of knowledge, different attitudes and practices regarding sexually transmitted infections and use contraception by age, educational level, nationality, employment status and place of residence. There are different views and practices regarding family planning, abortion and fertility by age, nationality, religions affiliation and place of residence. There is a difference in caring during the pregnancy, childbirth and postpartum care by age, nationality, education level, employment status and place of residence. There is a difference in the use and satisfaction of health care by age, nationality, education level, employment status and place of living. There is a low level of knowledge of respondents and differences in the level of knowledge about reproductive rights under the public-health determinants of age, nationality, education level, employment status and place of residence.

Key words: sexual and reproductive health; women in the reproductive period; public health determinants.

Defended: June 9, 2011.

Mentor: Prof. Dr. Elena Kjosevska.

Kiril Pashoski. Model for providing safety health technology in the food industry [MSc thesis]. Skopje, Republic of Macedonia: Cathedra of Hygiene, School for Public Health, Faculty of Medicine, University "Ss Cyril and Methodius"; 2011.

The HACCP is the international acknowledged system which guarantees the food safety. The HACCP concept is based on risk assessment in all food process production, trade and distribution, because foodstuff can be contaminated in each of those phases. The Republic of Macedonia has big possibilities for production and export of quality and safety food. Many producers and food operators in Macedonia make decisions for business according to concept HACCP, because they want to give to the consumers a safety and quality food. The European Union in its legislation has established HACCP as obligatory concept for third countries export as well as for our export of food in 2006, and from 2009 this concept will be obliged at domestic market, too. The objective of the thesis is to focus the public health aspects of implementing HACCP system in the example of the local building industry. The successful application of HACCP requires the full commitment and involvement of managerial and labor. It also requires multisectorial approach, and this multidisciplinary approach compared to a study include, where appropriate, expertise in agronomy, veterinary health, production, microbiology, medicine, public health, food technology, environmental health, chemistry and engineering.

Key words: HACCP, food safety; risk assessment; food operator; Republic of Macedonia. 
Defended: November 8, 2011.

Mentor: Scientific collaborator Dr. Vladimir Kendrovski.

Metodij Pashoski. Impact of the ambient temperature and occurrence of enterocolitis in Republic of Macedonia in context of climate change [MSc thesis]. Skopje, Republic of Macedonia: Cathedra of Hygiene, School for Public Health, Faculty of Medicine, University "Ss Cyril and Methodius"; 2011.

Data on the impact of the weather factor as ambient temperature to the disease are insufficient in the country and we need to adapt them in our thoughts as a potential additional factor which is associated with increasing rate of overall morbidity or specific as exemplified by the disease enterocolitis.

The main goal of this research is to show the public health aspects of the impact of weather and climatic temperature changes which occur on the enterocolitis in Macedonia with an emphasis on the need for any specific public health preventive measures in terms of adaption in the health sector to reduce burden of disease caused by the expected climate change.

The survey confirmed the ecological burden of the temperature and the vulnerability of the population with enetrocolitis diseases in Republic of Macedonia and in the examined cities in the country where the incidence of seasonality were determined by the values of the seasonal index/indexes for the Republic of Macedonia and the cities of Skopje, Bitola, Kumanovo, Strumica, Veles, and Stip. Seasonal index has the highest value in the summer months and lowest in winter.

The survey confirmed also the connection between the influence of temperature and enterocolitis occurrence with polynomial regression which examined the relationship of the dependent variables: enterocolitis cases with week distribution and independent variables: mean weekly maximum temperature for Skopje, Bitola, Kumanovo, Strumica, Veles, and Stip for the period 1994-2008. for all cities the value was $P<0.005$, which means that there is a statistically significant relationship between examined variables at 95\% level of confidence. Namely, the temperature rise is followed by an increase in the number of people suffering from enterocolitis.

The survey confirmed the connection between the influence of temperature and diseases in terms of relations of ratio rates as odds ratio- in terms of temperature change for $1^{\circ} \mathrm{C}$ and the occurrence of snterocolitis with Poisson regression which examined the relationship of the dependent variables: enterocolitis cases with week distribution and independent variables: mean weekly maximum temperature for Skopje, Bitola, Kumanovo, Strumica, Veles and Stip for the period 1994-2008. It was confirmed that each increase in temperature over $1^{\circ} \mathrm{C}$ will reflect in Skopje with an increase in the number of infected persons from enterocolitis to 2.95\%; in Bitola increase the number of people suffering from enterocolitis for $6.8 \%$, in Strumica for $7 \%$, in Kumanovo for $4.8 \%$; Veles for $6.4 \%$ and Stip for $4.6 \%$. According to the scenarios predicted the movement of enterocolitis in Macedonia in the period until 2050 only in function of temperature, if not carried out any adaption, is expected to increase for several percentage in cold months and in the warmer part of the year would be expected to increase by $15-30 \%$ enterocolitis morbidity depending on the cities in Macedonia expressed as monthly average daily value.

Key words: climate change; enterocolitis; ambient temperature; Republic of Macedonia; adaption.

Defended: November 8, 2011.

Mentor: Scientific collaborator Dr. Vladimir Kendrovski.

Gordana Antuleska-Belcheska. Public health and biomedical aspects of scoliosis among school children at the age of 7-14 years in the Republic of Macedonia [MSc thesis]. Skopje, Republic of Macedonia: Cathedra of Epidemiology and Biostatistics with Medical Informatics, Faculty of Medicine, University "Ss Cyril and Methodius"; 2011.

Background: Scoliosis is a three-dimensional deformity of the spine, which as a pathological condition is know and treated in the time of Hypocrites. Scoliosis is a problem which exists in all countries around the world, especially in the developing ones. In RM, scoliosis among school children at the age of 7-14 is represented by $7.5 \%$

Aim: To certify the representation of radiological diagnosed scoliosis among school children in RM, the specific types of scoliosis in relation to age, location, degree of scoliosis according to the angle of deviation of the spine, as well as to define the risk factors for the occurrence.

Study Design: Case - control study from causal type conducted on children at the age of 7-14.

Methods: In order to fulfill the purposes of the research, 
two groups were formed: examined and control group. Children were divided in three groups according to age: children at the age of 7-9, 10-12 and 13-14. A questionnaire was also prepared on the basis of recommendations by SRS. The questionnaire consists of 15 rules and was intended for parents. Statistical processing was done in Statistics for Windows 8.0.

Results: According to gender distribution, scoliosis is more likely in females, $64.49 \%$ in comparison to male children. Distribution according to age illustrates that scoliosis is most likely to appear among age group of 10$12,58.7 \%$. Juvenile and adolescent scoliosis is much more likely to appear in female children. The connection between the socio-economical status and scoliosis was also confirmed. Namely, 52.9\% of children from average socio-economical status according to FAS-scale has 2.18 times significantly greater risk of developing scoliosis. Ratio of scoliosis according to the place of living (urban and rural area) is 52.9\% : 47.1\%. Sitting in front of the computer, physical inactivity, as well as high $\mathrm{BMI}$ is a great risk factor for development of scoliosis. The questionnaire also confirmed low level of education among parents regarding this problem, $15.9 \%$. Symmetrical sports prevent scoliosis from development. Within the examined group of children, the division is made according to the level of scoliosis: mild, medium and severe scoliosis. Most often developed is the double scoliosis $66.87 \%$ in comparison to single thoracic $12.32 \%$ and lumbar $21.02 \%$ deviation. The angle of deviation (Cobb) moves in intervals of 9-78 degrees, with average value of $15.76 \pm 8.5$

Conclusion: First research from this type in the country, which gives information from essential significance for improvement and promotion of health, as well as improvement of primary prevention, all aiming at protection of child health, and thus creating a healthy society and realization of the Declaration of WHO "Health for everyone in the $21^{\text {st }}$ century".

Key words: scoliosis; risk factors; deviation of the spine; Cobb's angle; screening.

Defended: November 10, 2011.

Mentor: Prof. Dr. Beti Zafirova-Ivanovska.

Predrag Stanojevic. HPV infection at female population, public health problem on XXI century [MSc thesis]. Skopje, Republic of Macedonia: Cathedra of Epidemiology and Biostatistics with Medical Informatics, Faculty of Medicine, University
“Ss Cyril and Methodius”; 2011.

Objective: Cervical cancer and infection with HPV are both important public health problems in $\mathrm{R}$ Macedonia. The objective of this study was to establish the prevalence and type distribution of human papillomavirus (HPV) among women in $\mathrm{R}$ Macedonia, to determine the risk factors in cervical cancer and cervical intraepithelial neoplasia (CIN), and suggest the prevention measures. Methods: A cross-sectional study of 300 female patients separated in two groups: HPV+ and HPV. HPV and typing were examined by the polymerase chain reaction (PCR) and sequencing. Results: HPV DNA was detected in 121 patients, HPV 16 being detected in 21,5\% of causes, HPV 18 in 16,5\%, HPV 6 in 14,9\%, HPV 11 in $14,0 \%$, HPV 31 in 12,4\% and HPV 58 in 6,6\%. HPV DNA was detected in $47.9 \%$ female patients with CIN I-III and $\mathrm{Ca}$ in situ. Risk factors-the difference was significant at: first sexual contacts under 20 years age $(p=0.0001)$, sexual behavior - 3 and more partners during the life $(p=0.02)$, more than 2 abortions $(p=0.0007)$, not using condoms $(p=0.001)$. There is also significant difference at female patients with different level of education $(p=0.005)$, and at female patients with elementary information about HPV ( $p=0.002$ ). $79,65 \%$ of female patients are informed about HPV vaccine, but only 27,65\% know about efficiency of vaccine. Conclusion: prevalence of high risk types of HPV in Macedonia, without elementary information about HPV and preventive measures, without developed national protective program against HPV infection, deserve attention as it has important implications for the usefulness of vaccine and the choice of diagnostic methods.

Key words: Not available.

Defended: November 11, 2011.

Mentor: Prof. Dr. Rozalinda Isjanovska.

Irena Bogdanoska. Impact of workplace on the eating habits among workers [MSc thesis]. Skopje, Republic of Macedonia: Center for Public Health, Faculty of Medicine, University "Ss Cyril and Methodius"; 2011.

Introduction: The importance of nutrition in relation to the work process is an important factors that affects on the health of individual and community, because it is often difficult to have a proper healthy meal lunch during the working day. Because of the places where workers often go, during the lunch, outside of the office, there is high intake of energy food and low in mikronutriensi, which brings increasing to body, weight and thus directly 
affect the growth, development, reproduction and physical and mental condition of the individual. Goals: The main goal- to promote the importance of improving the workers health through the evaluation of habits and suggest a healthy and balanced regimen, specific goals-evaluation of eating habits of the examinated population group during the workday and assessment of the expectations of the examinees in terms of balanced food. Material and method: C A survey is realized on the field, with which a transaction was made in terms of the condition of the eating habits during working day. In the research 150 workers from REK Bitola surveyed, they are divided two groups, 120 workers that exposed to greater physical effort and work in manufacturing plants and plants to maintaining the mine and thermal power plants of Mining and Energy REK Bitola and 30 workers that work in nonmanufacturing plants and are exposed to less physical effort (Administration and the departments of planning and preparation). The questionnaire is the original study on the balanced food (Project Obesity through Offer and Demand). Results: For statistical processing and analysis of the supplied information, methods are used for descriptive and analytical statistics with statistical significance ( $p$ ) smaller than 0.05 is determined in the evaluation of the eating habits during the working day of the examined population group in relation of the control group where it is determined that mainly examined population group where it is determined that mainly examined population group practiced unvaried food. From the obtained information for the protects on the expectations population group in relation of balanced food it is determined that the appropriate information for a balanced food would have an important role in the change of eating habits. Conclusion: According to the results of the research we concluded that the workplace has a significant influence on eating habits. These results contribute for health promotion the of workers with suggestions of healthy and balanced food menus.

Key words: food; nutrition; employment; eating habits; balanced food menus.

Defended: December 29, 2011.

Mentor: Prof. Dr. Dragan Gjorgiev.

Suzana Mitrevska. The nutrition habits, the live style and the recognition of the risk-factors of cardiovascular disorders at the high school population in Republic of Macedonia [MSc thesis]. Skopje, Republic of Macedonia: Center for Public
Health, Faculty of Medicine, University "Ss Cyril and Methodius"; 2011.

The needs, challenges and consequences of the balanced or inappropriately balanced nutrition, differ in various stadiums of life: pregnancy; baby; childhood; adolescence; maturity and old age. One of the most important characteristics of the childhood is the continuous process of growth and development. The monitoring and evaluation of that process in that particular stadium is of an essential importance. The latest knowledge of the growing frequency of the risk-factors, especially for vascular disorders that are ranked as a first cause of mortality worldwide, in both developed and under developed countries, as well as the fact that the arteriosclerosis appears even in the childhood, point at the urgent need of undertaking preventive actions during the early age. The nutrition habits, the life style and the recognition of the risk-factors of the cardiovascular disorders, especially at school age, are very important and have major influence on the further development of the consciousness of this important group of population. The main goal of this research is to detect some of the main characteristics of the destructive life style ( inappropriate nutrition, physical inactivity, smoking, consuming alcohol), as well as to estimate the level of knowledge of the high school population in the Republic of Macedonia about the risk-factors that cause cardiovascular diseases, and also to suggest specific promotional programs for this target group. The research took place in 9 high schools in R. Macedonia (5 in Skopje and one in Strumica, Vinica, Bitola and Tetovo), including 347 high school students at the age of 17-18. The results showed that school students in the Republic of Macedonia demonstrate high-risk behavior in terms of their health (bad nutritional habits, smoking, insufficient physical inactivity, consuming alcohol etc.), but also most of them think that they are only partly informed about the riskfactors which lead to heart diseases and they lack information about the health nutrition.

Key words: cardiovascular diseases; nutrition; life style; adolescence.

Defended: December 29, 2011.

Mentor: Prof. Dr. Rozalinda Isjanovska.

Olivera Mojsovska Velickovski. Impact of the oral health on the quality of life among adult population in the territory of the City of Skopje, public health approach [MSc thesis]. Skopje, Republic of 
Macedonia: Cathedra of Epidemiology and Biostatistics with Medical Informatics, Faculty of Medicine, University "Ss Cyril and Methodius"; 2011.

Oral health represents inseparable part of general health and wellbeing of the individual. Good oral health means repaired dentition and the absence of any kind of pain in that area. The aim of this paper is to show the state of the mouth and teeth in adult population from 19 to 60 years and its impact on the quality of everyday life. You need to be seen whether the habits, behavior and personal attitude affect the condition of the mouth and teeth and how to inspire everyday problems, displaying the results and data on what factors affect self-awareness of oral health care and that socio-demographic factors are crucial for the differences in the state of oral health and what impact it has on social interaction, ability to work and having less quality of life due to problems with the mouth and teeth. The survey was conducted in several representative dental offices in the territory of Skopje, where randomly included 364 respondents who filled out a questionnaire and were reviewed by a dentist who noted the current state of teeth.

Then the statistical processing of data in SPSS system were divided into two groups $A$ and $B$, according to whether they visited a dentist in the last year or not.

The results showed more statistical significance in terms of multiple variables. It showed that social-demographic characteristics are important factors for treatment and care of the individual to oral health, the common reason for postponing a visit to the dentist, although in need of it, is because of fear of dental intervention, dental problems that impair social aspects of everyday life and dental problems that lead to poor nutrition, or difficulty while eating.

Finally concluded that factors residence, currently present toothache, inability to work due to dental problems, general ill health due to dental problems, remediation is an extra expense on the family budget, represent values that are statistically significantly independently associated with the conclusion that life is less quality, due to problems with teeth.

Key words: quality of life; oral health.

Defended: December 29, 2011.

Mentor: Prof. Dr. Biljana Taushanova. healthcare instructions in the tertiary health care [MSc thesis]. Skopje, Republic of Macedonia: Center for Public Health, Faculty of Medicine, University "Ss Cyril and Methodius"; 2011.

This master thesis is dedicated to analyzing the current situation regarding the implementation of the regulation on chemical safety and health at work in laboratories in healthcare instructions in the tertiary health care in Macedonia.

the aim of this research was to determine the degree of familiarity of health workers with the national legislation in the field of chemical management and safety and health at work, and especially, to analyze their familiarity with the rules for use and storage of certain chemicals; measures for safety and health at work; means of protection during work, emergency response, the use of signs and markings; training and management of chemical waste.

The survey was conducted in 8 (eight) laboratories in public health instructions of tertiary care where health workers are directly exposed to dangerous chemicals and the department responsible for storage and treatment of medical waste generated from the healthcare institutions. The instrument of this research was specifically designed questionnaire which was given to 100 participants.

The conclusion that emerges from this research is that in Macedonia there are institutions and legislation in the field of chemical management and safety and health at work, but the familiarity and implementation of regulations in the laboratories in healthcare institutions is very low. This confirms the fact that health workers do not have the necessary range of information and knowledge about the rules for use, labeling and storage of chemicals; laboratories in health care facilities do not have the proper equipment and proper personal protection for health workers, health workers don't receive adequate laboratory training; the measures for safety and health are not implemented in the workplace and there is lack of human resources and procedures for proper management of the chemical waste.

Key words: Not available.

Defended: December 29, 2011.

Mentor: Prof. Dr. Elisaveta Stikova.

Ana Shopova. Implementation of the regulation on chemical safety and health at work in laboratories in 